\title{
UNA APROXIMACIÓN PSICOANALIITICA ENTRE LA PULSIÓN Y EL SENTIDO OLFATIVO
}

\section{A PSYCHOANALYTIC APPROACH BETWEEN DRIVE AND OLFACTORY SENSE}

FRANCISCO JARAMILLO T.

Recibido: 4 de agosto de 2016 Aprobado: 27 de septiembre de 2016

* Pontificia Universidad Católica del Ecuador, Facultad de Psicología, Quito, Ecuador (hjaramillot@puce.edu.ec) 



\section{UNA APROXIMACIÓN PSICOANALIITICA ENTRE LA PULSIÓN Y EL SENTIDO OLFATIVO}

Francisco Jaramillo T.

PALABRAS CLAVE: pulsión, olfato, imagen inconsciente del cuerpo, carácter olisco, huella mnémica, significante.

KEY WORKS: drive, smell, unconscious body image, sniffed character, mnemic trace, signifier.

\section{RESUMEN}

Este ensayo propone trabajar las relaciones existentes entre la pulsión -concepto fundamental del psicoanálisis- con el sentido olfativo. Esta particular articulación, no ha sido abordada a profundidad desde de la teoría y clínica psicoanalítica, a excepción de unos pocos trabajos. La memoria olfativa se desarrolla desde que el niño se encuentra en el vientre materno. El poder abordar esta reflexión, permitirá a psicólogos y psicoanalistas tener una herramienta suplementaria en el trabajo clínico con niños, adolescentes y adultos.

\section{ABSTRACT}

This paper aims to work in the possible relations between drive, as a fundamental concept in psychoanalysis, with the olfactory sense. This particular joint has not been addressed in depth in psychoanalytical theory and clinic, except for a few authors. The olfactory memory is developed since the child is in the womb. The possibility of this reflection, will allow psychologists and psychoanalysts to have an additional tool in clinical work with children, adolescents and adults. 
Para iniciar este trabajo, es importante ubicar el tema de la pulsión, concepto inaugurado por Sigmund Freud. A lo largo de toda su obra se señalará que es un concepto que es complejo e inconcluso, pues trasmite una serie de encrucijadas en la teorización psicoanalítica. En los Tres ensayos de una teoría sexual, Freud (1905/2008) define a la pulsión como:

Por $<<$ pulsión $>>$ podemos entender al comienzo nada más que la agencia representante \{Repräsentanz\} psíquica de una fuente de estímulos intrasomática en excitaciones singulares provenientes de fuera. Así, <<pulsión $>>$ es uno de los conceptos del deslinde de lo anímico respecto de lo corporal. (p. 153).

Líneas más abajo del texto en mención, Freud explica una hipótesis provisional con respecto a los órganos del cuerpo.

(...) los órganos del cuerpo brindan excitaciones de dos clases, basadas en diferencias de naturaleza química. A una de estas clases de excitación la designamos como la específicamente sexual, y al órgano afectado, como la $<<$ zona erógena $>>$ de la pulsión parcial sexual que arranca de él. (Freud, 1905/2008, p. 153).

Las características esenciales definidas por Freud en Pulsiones y destinos de pulsión (1915a/2008) sobre la pulsión son: la fuente (Quelle), el esfuerzo (Drang), el objeto (Objekt) y la meta (Ziel).

La fuente de la pulsión se entiende aquel proceso somático, interior a un órgano o a una parte del cuerpo, cuyo estímulo es representado \{repräsentiert\} en la vida anímica por la pulsión. No se sabe si este proceso es por regla general de naturaleza química o también puede corresponder al desprendimiento de otras fuerzas, mecánicas por ejemplo. (Freud, 1915a/2008, pp. 118-119).

El esfuerzo de una pulsión se entiende su factor motor, la suma de fuerza o la medida de la exigencia de trabajo que ella representa \{repräsentieren\}. Ese carácter esforzante es una propiedad universal de las pulsiones, y aun su esencia misma. (Freud, 1915a/2008, p.117).

El objeto de la pulsión es aquello en o por lo cual puede alcanzar su meta. Es lo más variable en la 
pulsión; no está enlazado originalmente con ella, sino que se le coordina sólo a consecuencia de su aptitud para posibilitar la satisfacción. No necesariamente es un objeto ajeno; también puede ser una parte del cuerpo propio. (Freud, 1915a/2008, p. 118).

La meta de una pulsión es en todos los casos la satisfacción que sólo puede alcanzarse cancelando el estado de estimulación en la fuente de la pulsión. Los caminos que llevan a ella pueden ser diversos. (Freud, 1915a/2008).

En cambio sus distintos destinos se relacionan con: el trastorno hacia lo contrario, la vuelta hacia la persona propia, la represión y la sublimación.

Para Freud (1915a/2008), el trastorno hacia lo contrario: "se resuelve ante una consideración más atenta en dos procesos diversos: la vuelta de una pulsión de la actividad a la pasividad, y el trastorno en cuanto al contenido como es el caso del amor en odio". (p. 122).

Mientras que la vuelta hacia la persona propia es explicada por Freud desde el masoquismo, que vendría a ser un sadismo vuelto hacia el yo propio y la exhibición lleva incluido el mirarse el cuerpo propio (Freud, 1915a).

Los conceptos sobre la represión y la sublimación no son abordados a profundidad en este texto por Freud. Se sabe que el padre del psicoanálisis realizó un escrito sobre la sublimación pero fue destruido por su creador. Se podrá mencionar a través de Lacan (1964/2012) que la sublimación es también satisfacción de la pulsión a pesar que esté inhibida en cuanto a su meta. La sublimación no deja de ser una satisfacción de la pulsión, sin represión.

El texto sobre la represión fue redactado el mismo año que fue elaborado el trabajo sobre las pulsiones. Es importante acotar que para Freud (1915b/2008) la doctrina de la represión es el pilar fundamental sobre el que descansa el edificio del psicoanálisis.

Una de las formas para definir dicho concepto sería:

La represión no es un mecanismo de defensa presente desde del origen; no puede engendrarse antes que se haya establecido una separación nítida entre actividad conciente y actividad inconciente del alma, y su esencia consiste en rechazar algo de la conciencia y mantenerlo alejado de ella. Este modo de concebir la represión se complementaría con un supuesto, a saber, que antes de esa etapa de la organización del alma los otros destinos de pulsión, como la mudanza hacia lo contrario y la vuelta hacia la 
persona propia, tenían a su exclusivo cargo la tarea de la defensa contra las mociones pulsionales. (Freud, 1915b/2008, p.142).

Para Lacan, al efectuar una relectura de los textos freudianos, dirá que la pulsión es: "el montaje a través del cual la sexualidad participa en la vida psíquica, y de una manera que tiene que conformarse con la estructura de hiancia característica del inconsciente" (Lacan, 1964/2012, p. 183).

Lacan siguiendo el trabajo de Freud y de Abraham, apunta hacia las pulsiones parciales. No existiría una pulsión totalizadora. Para dar mayor énfasis a este punto se mencionará lo expuesto por Lacan en su seminario sobre Los Cuatro Conceptos Fundamentales del Psicoanálisis:

A saber que, en lo referente a la instancia de la sexualidad, la situación es la misma para todos los sujetos, así sean niños o adultos -todos se enfrentan sólo con la sexualidad que pasa por las redes de la constitución subjetiva, las redes del significante- la sexualidad sólo se realiza mediante la operación de las pulsiones en la medida en que son pulsiones parciales, parciales respecto de la finalidad biológica de la sexualidad. (Lacan, 1964/2012, p.184).

Las pulsiones por ser parciales no pueden estar desligadas con respecto al otro y al Otro. Para afianzar esta premisa se señalará:

"Este sujeto, que es propiamente el otro, aparece si la pulsión llega a cerrar su trayecto circular. Sólo con su aparición en el otro puede ser realizada la función de la pulsión". (Lacan, 1964/2012, p. 186).

Luego de este recorrido teórico, se resumirá al concepto de pulsión como una noción fronteriza entre el cuerpo y la psiquis. Para el psicoanálisis: "es un concepto básico que está destinado a dar cuenta a través de la hipótesis de un montaje específico, de las formas de relación con el objeto y de la búsqueda de satisfacción" (Chemama \& Vandermersch, 2004, p.568).

A partir de esta relación del sujeto con el otro, se podrá acotar que no existen zonas exclusivas corpóreas por donde las pulsiones transiten por caminos unidireccionales. Su meta no es otra que ese regreso en forma de circuito. (Lacan, 1964/2012). Es por ese motivo que en este artículo se propone trabajar algunas relaciones existentes entre el cuerpo, las pulsiones y los olores. La pregunta ¿De qué manera los niños y las niñas aprehenden de sus madres a identificar los olores que marcarán sus recuerdos in- 
fantiles en su psiquismo? es una de las hipótesis planteadas para este artículo. El niño es apalabrado antes de su concepción por el deseo de sus progenitores. Es importante acotar ¿cómo es percibido el niño? y ¿cómo este nuevo sujeto en construcción percibe su mundo a través de los otros? Específicamente, se tomará en cuenta el planteamiento de una pulsión odorífera como parte de la constitución subjetiva.

Desde estas aproximaciones, surgen adicionalmente otras preguntas para este artículo: ¿Qué se puede decir sobre los olores como objetos parciales en el psiquismo humano? ¿Existe una pulsión odorífera parcial?

Así se señalará que los objetos pulsionales son innumerables y su fin no puede ser alcanzado sino de manera provisional. La satisfacción, desde una lectura freudiana, se dirá que no es completa. La tensión renace enseguida. El objeto es en parte inadecuado para su satisfacción absoluta. Por lo tanto, su función nunca se cumple definitivamente (Chemama \& Vandermersch, 2004).

Martine Lerude, psicoanalista miembro de la Asociación Lacaniana Internacional, realizando una bisagra desde Freud con Lacan, dirá que la pulsión es un concepto que se articula entre el cuerpo y el lenguaje. (Lerude, 2013). Siguiendo a esta autora, se podrá mencionar la importancia que le dieron los primeros analistas con relación a la erotización de los orificios corporales. Específicamente, se podrá mencionar a Karl Abraham que fue el pionero en señalar el concepto de objeto parcial.

Para dicho autor, la pregunta central sobre las pulsiones estaba ligada a: ¿cómo pueden los objetos relacionados con las pulsiones ser investidos y erotizados hasta el punto de venir al lugar de la investidura sexual? (Abraham citado en Lerude, 2013). A partir de esta pregunta, surgirá el debate con mayor rigor en el grupo freudiano. Desde su punto de vista, Freud, establece que la sexualidad genital se sostiene por los objetos parciales. Se puede llamar a esto el campo del erotismo como lo menciona Lerude (2013).

El mito de pensar que existe una pulsión sexual unificadora, como se mencionó antes, es una utopía. Lo que hay en el psiquismo humano son pulsiones parciales que ejercen sus actividades independientemente. Luego podrán converger para entrar al servicio de la reproducción como lo acota Lerude (2013).

Sin embargo, tomando en cuenta a Marcel Czermak (1998-1999), se podrá precisar con respecto a la relación entre la pulsión y el objeto. Desde estas conceptualizaciones se dirá:

Quiero decir que la función, la pulsionalidad es parcial. Acepto o 
no comer, acepto o no escuchar, etc. Digo sí o digo no, es decir, las funciones biológicas desnaturalizadas por el hecho del lenguaje se paralizan. Entonces no es el objeto que como tal es parcial, sino que nuestras funciones $y$ nuestras pulsiones toman parte" (Czermak, 1998-1999, p. 19).

Dentro del campo de estas incompletudes, aparecen en el ser humano, los diferentes objetos parciales que mencionaba Freud como pueden ser: el seno, las heces, el niño y el pene. Para Lacan existen dos objetos adicionales que se relacionan más cercanamente al deseo: la mirada y la voz.

Desde el momento que un niño está en el vientre materno, puede captar una serie de estímulos que vienen del exterior. Es la madre quien genera el vínculo entre la periferia y su vientre. Es sabido que cuando nace un niño, algunos pediatras le sugieren a la madre no ponerse perfume o cremas para que el recién nacido pueda captar el olor de su progenitora.

Incluso, se podrá mencionar como hipótesis: el reconocimiento odorífero del bebé en formación con su madre, lo podría obtener desde el desarrollo intrauterino.

Experimentos realizados con niños de tres a diez días de nacidos, muestran que la ropa impregnada con el olor de su madre les produce un efecto sedante comparable al de su presencia física, mientras que si la ropa es de otra parturienta el niño continúa inquieto. (Porter, R. citado en Ortiz, F, 2013).

La madre ocupa el papel de pantalla protectora y a su vez es quien permite la trasmisión de sensaciones y excitaciones en el aparato psíquico del bebé Este "préstamo" pondrá de manifiesto la particular estructuración subjetiva que la madre genera en el cuerpo de su hijo. (Moizeszowicz \& Moizeszowicz, 2000).

Otros autores, entre ellos Dolto (1986) y Nasio (2008), consideran que desde la vida intrauterina hasta los tres años aproximadamente, se impregnan en las huellas mnémicas ${ }^{1}$ del niño, una serie de imágenes inconscientes en su cuerpo. Es un lenguaje que habla y dice de ese sujeto a través de silencios y de sensaciones antiguas olvidadas.

Se definirá a la Imagen Inconsciente del Cuerpo como: "el conjunto de las primeras y numerosas impresiones grabadas en el psiquismo infantil por las sensaciones corporales que un bebé, o incluso un feto, experimenta en el contacto con su madre, en el contacto car-

1 Son las formas bajo las cuales los acontecimientos o, más simplemente, el objeto de las percepciones, se inscriben en la memoria, en diversos puntos del aparato psíquico (Chemama \& Vandermersch, 2004). 
nal, afectivo y simbólico con su madre". (Nasio, 2008, pp. 20-21).

Por lo tanto, se podrá hablar de un estadio neonatal u olfativo respiratorio leyendo a Nasio con Dolto. En este momento lógico de la vida de un niño: "Toda vivencia afectiva y corporal intensa, sea o no consciente, siempre deja su huella indeleble en el inconsciente. Por todo esto afirmaremos que la Imagen Inconsciente del Cuerpo es, para decirlo apropiadamente, una memoria de nuestro cuerpo infantil" (Nasio, 2008, p. 25).

Dentro del estudio de la Imagen Inconsciente del Cuerpo, según Dolto (1986), se encuentra dividido en tres grandes componentes: Imagen de base, Imagen funcional e Imagen erógena (Nasio, 2008). Esencialmente, para este artículo en construcción, se pondrá mayor énfasis en la Imagen funcional. Esta última, apunta hacia la imagen de la sensación de un cuerpo agitado y febril como lo acota Nasio (2008).

Para dicho autor, Dolto (1986) distingue entre los objetos concretos y los sustanciales como el alimento y los excrementos -los cuales intervienen en el contacto corporal entre la madre y el niño- los objetos sutiles que podrían ser percibidos a distancia como una mirada tierna, el timbre de una voz o el delicado y suave aroma de una piel (Nasio, 2009).

A través de estos primeros contactos entre la madre y el niño, el infante se irá ligando libidinalmente con los objetos que más le causan placer y satisfacción. Las imágenes olfativas podrían ser, una de las percepciones que más impacto producirían en la memoria infantil.

Cuando un objeto nos emociona, una música nos sensibiliza, un perfume nos cautiva o la idea de un dolor visceral nos angustia, podemos estar seguros, de que ya hemos vivido una sensación visual, auditiva, olfativa o dolorosa que se inscribió en el inconsciente y acaba de reanimarse en el presente. Generalicemos. Toda sensación vivida intensamente en la infancia imprime en nuestro inconsciente una imagen original (protoimagen) que se reactivará como una imagen consciente $y$ conmovedora cuando aparezca una sensación semejante o un elemento asociado a ella. Veremos que la imagen original 0 protoimagen también puede exteriorizarse en una manifestación corporal espontánea (imagen actuada) (Nasio, 2009, p. 68).

Lo olfativo, que fue generador de un gran placer durante la fase oral, que apoyó a su vez en el establecimiento del primer vínculo entre la madre y el bebé, tomando en cuenta este sentido antes 
que se desarrollasen la vista y el tacto, propiciando la "devoración" de la madre en un nivel molecular y que causó después una gran satisfacción durante la fase anal con el juego de intercambios a través de lo excrementicio según la explicación freudiana, cae en uno de los destinos de la pulsión como es la represión (Ortiz, 2013). Habrá que tomar en cuenta lo explicado por Freud (1905) con respecto a los diques psíquicos que se relacionan entre sí. El asco, la vergüenza y la culpa estarían articulados con lo reprimido.

Desde una coyuntura entre la clínica con la teoría, se retomará al autor Karl Abraham (1921/1994) quien realiza una descripción clínica muy importante en cuanto a la teoría del carácter anal y sus relaciones con los olores. Dicho autor parte del trabajo realizado por Freud (1908), titulado Carácter y Erotismo anal. Abraham realiza una observación clínica importante indicando lo siguiente:

Las personas desprovistas de una gratificación genital normal tienden por lo general a tener mal genio. Características faciales significativas de las personas, me parecen ser una constante tensión de la línea de los orificios nasales, y una ligera elevación del labio superior. En algunos casos, esto da la impresión de que es- tán constantemente husmeando algo. Probablemente este rasgo sea atribuible a su placer coprofíli$\mathrm{co}^{2}$ de oler. En el caso de un hombre que mostraba este tipo de expresión facial, observé una vez que parecía estar constantemente oliéndose a sí mismo. ${ }^{3}$ Alguien que lo conocía dijo que, efectivamente tenía el hábito de olerse las manos y todo objeto que recogía. Debo agregar que exhibía los típicos rasgos de carácter anales en una forma marcada. (Abraham, 1921/1994, p. 300).

Con esta viñeta clínica, se podrá decir que este rasgo de "husmear" ciertos olores, se lo obtiene a una edad cuando el niño o la niña comienzan a explorar el mundo y cómo sus padres o protectores reaccionan frente a su curiosidad. Son los adultos quienes trasmiten consciente o inconscientemente su forma de investigar. En este caso, a través de un olfato ligado a los objetos excrementicios. El mundo de los olores para los seres humanos va más allá del instinto animal. Como lo acota Lacan (1964/2012) siguiendo a Freud, la eco-

2 Según la DRAE (2016), la coprofilia es definida como la atracción fetichista por los excrementos.

${ }^{3}$ Apunta esta observación clínica hacia el destino de la pulsión nombrado por Freud como la vuelta hacia la persona propia. Este señalamiento es realizado por el autor de este artículo. 
ReVista PUCE. ISSN 1390-7719. Núm.103. 3 de mayo de 2016 -

nomía del deseo implica otras zonas que no son las clásicamente conocidas como erógenas. El cuerpo humano que está atravesado por la palabra y por donde los bordes se expresan aparece el circuito pulsional que va más allá de una simple necesidad.

Otra manifestación que puede estar atada a esta exploración olfativa del niño, es la mencionada por Donald Winnicott (1951/1999). Dicho autor inglés, elabora la teoría relacionada con los objetos y los fenómenos transicionales. Lo transicional le permitirá al infante ubicar una zona intermedia existente entre lo subjetivo y lo que es percibido objetivamente. También le asentirá al niño, reconocer su yo y su no-yo. Podrá colocar al objeto fuera, adentro o en el límite entre el adentro y el afuera. Adicionalmente, le brindará al niño la capacidad de: crear, imaginar, inventar, concebir un objeto e instituir con él una relación afectuosa (Chemama \& Vandermerch, 2004).

En este trabajo, Winnicott hace mención que la madre o su sustituta, deja que este objeto elegido por el niño, se ensucie e incluso huela mal. La madre sabe que si lo lava constantemente podría existir una ruptura en torno a la continuidad de la experiencia del pequeño. Lo que podría ocasionar una destrucción del significado que el niño le da a determinado objeto (Winnicott, 1951/1999).
Cabe señalar cómo cada niño inviste pulsionalmente al objeto elegido. Y dentro de esta investidura está el olor y otras características adyacentes que el niño faculta al objeto escogido. Es importante mencionar que estos objetos serán sustituidos a lo largo de la vida de los seres humanos. No hay un objeto totalizador que venga a taponar la falta de un sujeto tachado, de un sujeto que se encuentra en el lenguaje. Lacan reconoce la importancia de la observación realizada por Winnicott. Dicha teorización nos remite al registro del falo. Si seguimos con rigor su sistemática, cada juguete debe ser tomado como sustituto del objeto que causa el deseo (pequeño a), también dentro de la lógica del objeto de goce y relacionada como significante de la falta. Es por eso que el jugar para el niño representa: insistencia, goce y repetición. Esta dimensión abre la posibilidad para que el infante se ubique en la transicionalidad. La madre toma al niño mismo como transicional para ella y no como su realización fálica definitiva (Jerusalinsky, 2000).

Pero ¿qué pasa cuando estas primeras relaciones con la madre podrían resultar caóticas y repugnantes? Tal es el caso descrito desde la literatura por Patrick Süskind en su novela titulada El Perfume. Se tomará en cuenta la descripción que hace dicho autor, sobre el nacimiento de Jean-Baptiste Grenouille, 
protagonista de la novela. Esta representación realizada en París, nos remonta al año de 1738.

Para contextualizar lo vivido en el siglo XVIII en París, se mencionará lo expuesto por Süskind con respecto a los olores de la ciudad:

En la época que nos ocupaba reinaba en las ciudades un hedor apenas concebible para el hombre moderno.

Las calles apestaban a estiércol, los patios interiores apestaban a orina, los huecos de las escaleras apestaban a madera podrida y excrementos de rata.

(...) Hombres y mujeres apestaban a sudor y a ropa sucia, en sus bocas apestaban los dientes infectados, los alientos olían a cebolla y los cuerpos, cuando ya no eran jóvenes, a queso rancio, a leche agria y a tumores malignos. (Süskind, 1987, p. 9).

Con esta corta pero esclarecedora aproximación, se concatenará el nacimiento de Jean-Baptiste Grenouille. A continuación, se realizará una cita textual en donde se describe el momento antes del alumbramiento:

${ }^{4}$ El significado del apellido del protagonista de la novela, literalmente, viene a ser rana, traducido del francés al castellano.
(...) Y cuando comenzaron los dolores del parto, se acurrucó bajo el mostrador y parió allí, como hiciera ya cinco veces, y cortó con el cuchillo el cordón umbilical del recién nacido. En aquel momento, sin embargo a causa del calor y del hedor, que no percibía como tales, sino como algo insoportable y enervante -como un campo de lirios o un reducido aposento demasiado lleno de narcisos-, cayó desvanecida debajo de la mesa y fue rodando hasta el centro del arroyo, donde quedó inmóvil, con el cuchillo en la mano. (Süskind, 1987, p. 11)

La madre del niño, a pesar de estar rodeada de olores fétidos y repugnantes como lo son los restos de pescados en un mercado, pudo alucinar olores de una fragancia agradable momentos antes del parto. Con relación al momento del nacimiento, se recogerá la siguiente cita:

Gritos, corridas, la multitud se agolpa a su alrededor, avisan a la policía. La mujer sigue en suelo con el cuchillo en la mano; poco a poco recobra el conocimiento. ¿Qué le ha sucedido? -Nada.

¿Qué hace con el cuchillo? 
-Nada.

¿De dónde procede la sangre de sus refajos?

-De los pescados.

Entonces, de modo inesperado, la criatura que yace bajo la mesa empieza a gritar. Todos se vuelven, descubren al recién nacido entre un enjambre de moscas, tripas y cabezas de pescado y lo levantan. (Süskind, 1987, p.11-12).

A partir de estos acontecimientos como lo relata Süskind, la madre es apresada y sentenciada a muerte. Luego, el niño es cuidado por varias nodrizas. Una de ellas menciona que el niño bastardo "no huele a nada".

Hace mención esta mujer que sus hijos huelen a seres humanos mientras que Jean-Baptiste no es "percibido" por la niñera como "humano" 5 . Incluso es considerado como una criatura satánica que denotaba un hambre insaciable. Es importante tomar en cuenta estas primeras aproximaciones que se podrán realizar sobre este niño. Este ser humano nace en un lugar totalmente insalubre y maloliente. Su madre no lo quería traer al mundo. Las autoridades deciden que esta mujer -quien arrojó a su bebé- so-

${ }^{5}$ Humano, etimológicamente viene de la palabra humus, tierra. Para Lacan (1969-1970) el ser humano se llama así porque es el humus del lenguaje. bre las vísceras de los pescados, debe ser apresada y posteriormente decapitada. El niño nace y sobrevive pese a todos estos contratiempos.

Estos primeros momentos marcarán la vida de Jean-Baptiste, personaje obsesionado con los olores, el cual "roba" los aromas de veinticinco doncellas durante toda la novela. Él nunca pudo reconocer su propio olor humano ${ }^{6}$. Cuando recibió su sentencia de muerte, producto de los asesinatos que cometió, le preguntaron sobre su último deseo. Él respondió que no quería "nada". Esa misma nada que fue mencionada por su madre cuando nació y por sus nodrizas que se referían a él como alguien "que no olía a nada".

Finalmente, cuando fue apresado por sus crímenes cometidos, abre el frasco donde se encontraban las fragancias concentradas de su siniestra creación. Luego será matado y devorado por una multitud que percibe un olor extraordinario. La masa engulle a Jean-Baptiste.

Cabe la siguiente pregunta en este momento: ¿cuán importante es el reconocimiento de su propio olor a través del Otro primordial para la constitución del yo en el niño? ¿Cuáles podrían

${ }^{6}$ En este pasaje de la novela, se podrá pensar lo expuesto por Freud (1915 a) con respecto a los destinos de la pulsión. Específicamente sobre la vuelta hacia la persona propia. Jean-Baptiste manifiesta la imposibilidad de oler su propio cuerpo. 
ser los efectos de este fenómeno psíquico en la construcción subjetiva?

Fabián Ortiz (2013), hace mención sobre el carácter olisco en los seres humanos. Se basará en lo descrito por Flora Chade (2005). Sobre este aspecto se aludirá lo siguiente:

El significado de la palabra olfato, de hecho ya remite a una cualidad de quien huele. Proviene del latín olfatus, es el "sentido corporal con el cual se perciben los olores" pero también, figuradamente nos envía a la "sagacidad con que uno descubre o entiende lo disimulado o encubierto". (Ortiz, 2013, p. 9).

Más adelante, comenta ciertas particularidades de las personas que poseen dicho carácter:

La persona de carácter olisco no confía, re-cela, lo que remite, por oposición, a la entrega total que el niño tiene con su madre: para creer lo debe hacer "en confianza", mientras que si este pacto tácito se quiebra-real o alucinadamente- el pequeño se desanimará (sufrirá el des-aliento), crecerá temeroso, re-celoso y en adelante se protegerá del miedo a ser abandonado volviéndose olisco, es decir, suspicaz, delicado, susceptible de ofenderse con facilidad (Ortiz,2013, p. 9) .

Se podrá decir entonces que es a través del Otro primordial (la madre o su sustituta) que el niño puede encontrar seguridad en su propio cuerpo.

El bebé no dispone de la comprensión del lenguaje para ser informado de los deseos de la madre, ni para informarle sobre sus necesidades e inquietudes. El sistema del lenguaje preexiste al niño, pero fuera de él. Se hace entonces necesario que el niño se inscriba en el orden del lenguaje, incorporándolo a sí mismo para conseguir la asunción de toda su condición humana. (Jerusalinsky, 2011, p. 62).

La madre es la encargada de leer el cuerpo de su hijo. Dependerá de cómo fue leído el cuerpo de la madre para que ella trasmita su lectura en el cuerpo del infante. La madre tiene las claves del cuerpo del niño como lo menciona Jean Bergès en su ponencia sobre los niños hiperkinéticos (1998). La madre le permite a través de la trasmisión de sus significantes encontrar sus propias claves y enigmas al niño. El cuerpo del pequeño es leído por la madre y/o sus sustitutos. 
Entonces es importante interrogarse sobre: ¿cómo la madre articula el tema de los olores con sus significantes?

Para retomar lo expuesto en líneas anteriores, es significativo mencionar las palabras de las nodrizas en la novela El Perfume. El hecho de haber nominado el cuerpo de Jean-Baptiste "sin olor". Este punto es importante aludirlo, en cuanto a su constante búsqueda por el encuentro de su olor corporal en los otros: "el robo de olores de las doncellas" a través del asesinato de sus cuerpos y la formación del perfume siniestro. ¿Cómo pudieron marcar estos significantes en el psiquismo de este niño para que esté constantemente obsesionado en la búsqueda de lo inasible, de lo irrepresentable en su propio cuerpo? Al parecer, el circuito de sus pulsiones, incluida la pulsión odorífera falló desde sus orígenes cuando su madre quiso matarlo en el momento de su nacimiento alrededor de un ambiente nauseabundo. También se puede acotar el rechazo que vive el niño cuando las nodrizas no le acogen en sus regazos. Es un niño que no olía a nada.

Para concluir con este escrito, se podrán recapitular algunas hipótesis planteadas durante el transcurso del mismo. El tema relacionado con la pulsión ha sido y viene siendo un tema complejo en la teoría de Freud. No existe un cierre absoluto en cuanto a este trabajo pre- sentado por el padre del psicoanálisis. Sin embargo, se podrá mencionar que más allá de ser un concepto limítrofe entre el psiquismo y el soma, permite sostener una teoría del sujeto que no únicamente se queda en lo anatómico-fisiológico como algo primordial sino que apunta hacia una reflexión del aparato psíquico articulándolo con el lenguaje. Lacan dentro de su teoría mencionaba que el inconsciente está estructurado como un lenguaje. El lenguaje nos pre-existe por ser sujetos insertos en la cultura.

En este trabajo se tomaron concepciones de psicoanalistas contemporáneos como Martine Lerude (2013) la cual formula a la pulsión como un concepto en donde se articula el cuerpo y la palabra. Es importante mencionar que lo fundamental no es el objeto per se sino la relación existente entre el sujeto y el objeto. Allí se contornean las pulsiones parciales en los cuerpos de los seres deseantes.

En este artículo, se elabora la relación que tendría la vinculación madre-hijo y las huellas mnémicas inscritas en el inconsciente. Es importante formular la hipótesis relacionada con la inscripción de los olores y demás percepciones primarias que dejaron huella en el inconsciente del niño como lo acotan Dolto (1986) y Nasio (2008) respectivamente.

Es de suma importancia encontrar las relaciones que existirían entre 
estas primeras impresiones odoríferas y los efectos que podrían tener en cada uno de los sujetos. Se podrá descubrir, como en el caso descrito por Abraham (1921/1994), las diversas relaciones con respecto al Carácter y Erotismo Anal estudiado por Freud y asociado con los olores coprofílicos.

Se ha mencionado también el carácter olisco que pueden presentar algunas personas Ortiz, (2013) y Chade (2005). Según dichos autores, son sujetos que logran presentar ciertas características que perdurarán durante su vida y que fueron generadas a partir de las primeras relaciones con su madre o su sustituta. Podrán presentar signos de desconfianza, re-celo y perspicacia.

También se ha podido realizar un análisis conciso de la obra de Patrick Sūskind, titulada El Perfume. Se puso énfasis, principalmente, en el acto del nacimiento de Jean-Baptiste Grenouille, el contexto histórico donde se generó este acontecimiento, la relación con su madre y las siguientes nodrizas que se hicieron cargo de él. Uno de los puntos relevantes de esta historia novelesca es el hecho de haber sido nombrado como un "bastardo que no tiene olor". Esta huella mnémica, generará a lo largo del relato, la búsqueda incansable de su propio olor asesinando a veinticinco doncellas.

Finalmente, se mencionará la importancia de acoger en la clínica, el discurso de los pacientes en torno a sus olores y a sus recuerdos que provienen de la infancia. Estas reminiscencias generalmente son olvidadas o son inhibidas pero se actualizan cuando son mencionadas en el transcurso de las sesiones, trayendo a colación una serie de sensaciones que en algunos casos marcaron una huella indeleble en el psiquismo de cada persona. Freud hacía mención que la representación se reprime mientras que el afecto ligado a la misma se mantiene en la consciencia.

A partir de estas reflexiones, el terapeuta podrá tener un dispositivo adicional para explorar y analizar algunos elementos qaue no son tomados en cuenta en un trabajo analítico en muchas ocasiones. Así se encontrará, un punto anexo sobre las relaciones existentes entre el lenguaje y el cuerpo. Los olores y la capacidad de percibirlos -más allá de su parte real que en cada sujeto puede generar placeres, displaceres y goces- van a estar articulados con la palabra en los seres humanos. Esta conjetura marca la diferencia entre los seres humanos y los animales. Muchos mamíferos podrán tener un olfato más sagaz que los seres humanos; sin embargo, la diferencia radica en poder simbolizar estas percepciones dando un nuevo significado en cada uno de los seres hablantes. Esta es la tarea que el analista puede encontrar en cada analizante mientras escucha a cada suje- 
ReVista PUCE. ISSN 1390-7719. Núm.103. 3 de mayo de 2016 -

to mencionar sus distintas percepciones de todo tipo a lo largo de un trabajo atravesado por la palabra.

\section{Bibliografía}

Abraham, K. (1994). Psicoanálisis Clínico (1921). Buenos Aires: Lumen. Hormé.

Bergès, J. (1998). Los niños hiperkinéticos. Recuperado de: http://www. freud-lacan.com/index.php/fr/

Chemama, R. \& Vandermersch, B. (2004). Diccionario del Psicoanálisis. Buenos Aires: Amorrortu editores.

Czermak, M. (2002). Algunas vías fundamentales de la psicosis. La letra. Quito. 7-8. pp. 18-27.

Dolto, F. (1984). La Imagen Inconsciente del Cuerpo. Barcelona: Paidós Ibérica.

Freud, S. (1905/2008). Tres ensayos de teoría sexual. O.C. (Vol. 7). Buenos Aires: Amorrortu editores.

Freud, S. (1908/2008). Carácter y erotismo anal. O.C. (Vol. 9). Buenos Aires. Amorrortu editores.

Freud, S. (1915a/2008). Pulsiones y destinos de pulsión. O.C. (Vol. 14). Buenos Aires: Amorrortu editores.

Freud, S. (1915/2008). La represión. O.C. (Vol. 14). Buenos Aires: Amorrortu editores.

Moizeszowicz J, \& Moizeszowicz M, (2000), Psicofarmacología y Territorio freudiano. Buenos Aires: Paidós.

Jerusalinsky, A. (2011). Psicoanálisis del autismo. Buenos Aires: Nueva Visión. 
Jerusalinsky, A. (2000). Psicoanálisis en problemas del desarrollo infantil. Buenos Aires: Nueva Visión.

Lacan, J. (1969-1970/2008). El reverso del psicoanálisis. (Libro 17). Buenos Aires: Paidós.

Lacan, J. (1964/2012). Los Cuatro Conceptos Fundamentales del Psicoanálisis. (Libro 11). Buenos Aires: Paidós.

Naranjo, G. (comp.) (2013). Trayectoria. 20 años de transferencia de trabajo con la Asociación Lacaniana Internacional. Quito: Rayuela editores.

Nasio, J. (2008). El cuerpo y sus imágenes. Buenos Aires: Paidós.

Ortiz, F. (2013). ¿A qué huele una pulsión? XIII Jornadas del EPBCN: Aperturas en psicoanálisis. Pp. 1-11. Recuperado de: http://www.epben.com/publicaciones-psicoanaliticas/2014/04/a-que-huele-una-pulsion/

RAE (2016). Diccionario de la Lengua Española. Recuperado de: http://dle. rae.es/?id=AmA6L9L

Süskind, P. (1987). El perfume. Historia de un asesino Barcelona: Editorial Seix Barral.

Winnicott D.W., (1999). Escritos de Pediatría y Psicoanálisis. Barcelona: Ed. Paidós. 